\title{
¿QUIÉN LO HIZO? DATOS SOBRE LA INVESTIGACIÓN DE DELITOS DE SANGRE EN AL-ANDALUS
}

\author{
MANUELA MARÍN \\ Instituto de Filología, CSIC, Madrid
}

Uno de los ejemplos más conocidos, en la historia de al-Andalus, de investigación criminal, es el protagonizado en Córdoba por el wäli l-madina Muhammad b. al-Salīm. Recién nombrado para este cargo por el emir 'Abd al-Raḥmān II, Ibn al-Salīm fue informado del hallazgo de un hombre asesinado en el barrio de al-Qașșabin; el cadáver se encontraba dentro de un serón. La eficaz acción policial de Ibn al-Salīm, que interrogó a los fabricantes de serones y pudo identificar a quien lo había comprado, en cuya casa se hallaron ropas del muerto, fue recompensada por el emir con la concesión del título de visir ${ }^{1}$.

Las pesquisas policiales eran necesarias cuando no se contaba con testigos presenciales de un crimen de sangre, cuando faltaba la confesión del o de los culpables del crimen o cuando las circunstancias extraordinarias del caso así lo aconsejaban, como sucedió tras el asesinato de Abū Marwān al-Ṭubnī en 457/1065 2 . El derecho penal

${ }^{1}$ El relato de los hechos, en Ibn al-Qūtīya, Ta'rỉj iftitāh al-Andalus, ed. al-'Arabī, I., Argel, 1989, 63-64. Muhammad b. al-Salìm había sido gobernador de Toledo, nombrado en 232/846-47 y destituido al año siguiente (Ibn Hayyān, Al-Muqtabis min anbā' ahl al-Andalus, ed. Makkī, M. 'A., Beirut, 1973, 1-2). Era también wālī l-madina de Córdoba durante el proceso por blasfemia contra el hermano de 'Aŷab, según informa Ibn Hārit al-Jušanī, Quḍāt Qurțuba, ed. al-Abyārī, I., El Cairo, 1982, 132. Se ha venido datando este proceso en 237/851; M. Fierro ha propuesto situarlo entre $234 / 848$ y $238 / 852$, de acuerdo con la relación de jueces de Córdoba suministrada por Ibn al-Qūtiya (Fierro, M., La heterodoxia en al-Andalus durante el periodo omeya, Madrid, 1987, 58-59). Véase también, para Ibn al-Salīm y su familia, la nota 7 (p. 410-12) de M. 'A. Makkī a su edición de al-Muqtabis.

2 Cf. Molina López, E., «L'attitude des juristes de al-Andalus en matière de droit pénal. A propos d'une publication récente sur le thème», Le patrimoine andalous dans la culture arabe et espagnole, Túnez, 1991, 155-91; Marín, M., Mujeres en al-Ándalus, Madrid, 2000, 698-700, y el estudio monográfico que le dedica Christian Müller en este mismo volumen de Al-Qanțara («L'assassinat du savant Abū Marwān al-Ṭubnī: drame familial et judiciaire»).

Al-Qanțara XXVI, 2 (2005) 405-424 
islámico establecía, por su parte, toda una serie de normas sobre los procedimientos de prueba, castigo y compensación de los delitos de sangre, recogidas tanto en tratados de fiqh como en las colecciones de «casos legales» o de consultas jurídicas ${ }^{3}$. Cuando, como en el caso de al-Ṭubnī, se pueden manejar y contrastar entre sí informaciones procedentes de fuentes jurídicas y crónicas históricas, se obtiene un cuadro detallado - aunque siempre menos completo de lo que se desearía- de las repercusiones de un asesinato tanto en el piano individual como en el social. Sin embargo, y como es bien sabido, muchas de ias consultas jurídicas conservadas carecen de referentes cronológicos o de otro tipo, y su análisis contribuye mucho más al estudio de la evolución de la jurisprudencia que al de las implicaciones sociales de los hechos que describen ${ }^{4}$.

En las páginas que siguen voy a tratar dos aspectos de la investigación sobre crímenes de sangre en textos andalusíes - sobre todo, pero no exclusivamente, jurídicos - en los que se da la circunstancia de que sus protagonistas son personajes históricamente bien documentados. Ello permite afinar la percepción sobre las implicaciones de cada caso, las diferencias de opinión entre los juristas y la aplicación práctica de las normas legales.

\section{Inculpación de un delito de sangre por parte del agredido (tadmiya)}

En su extensa colección de casos legales, al-Burzulī (m. 841/1438) se pronuncia respecto a la tadmiya afirmando: «hoy día la práctica de los jueces ( 'amal) en Túnez es abandonarla. Eso mismo se ha transmitido de los andalusíes a propósito de la cuestión del alfaquí al-Lu'lu'ì, que es bien conocida y ha sido mencionada por los historiadores» ${ }^{5}$.

\footnotetext{
${ }^{3}$ Un buen resumen de la teoría legal, en Arévalo, R., Derecho penal islámico. Escuela malekita, Tánger, 1939. Véase también Chalmeta, P., «Acerca de los delitos de sangre en al-Andalus durante el Califato», El saber en al-Andalus. Textos y estudios II, ed. Carabaza Bravo, J.M. y Essawy, A.T.M., Sevilla, 1999, 45-64.

${ }^{4}$ Cf. Hallaq, W.B., «Murder in Cordoba: Ijtihäd, Iftä' and the Evolution of Substantive Law in Medieval Islam», Acta Orientalia, 55 (1994), 55-83.

5 Al-Burzulī, Ŷāmi' masā'il al-ahkām li-mā nazala min al-qaḍāyā bi-l-muftīn wa-l-hukkäm, ed. al-Hīla, M. H.., Beirut, 2002, VI, 59.
} 
La tadmiya se consideraba uno de los fundamentos posibies de la prueba deil delito y consistía en la acusación hecha por un herido grave, atestiguando la personalidad de su agresor ${ }^{6}$. En al-Andalus se conocen casos concretos de ejercicio de esta clase de inculpación, como el protagonizado por una mujer llamada Fātima bt. 'Alī, recogido en


de modelos de documentos notariales incluyeron en sus colecciones formularios para esta clase de acusación; así lo hicieron Ibn al-'Attāar (m. 399/1009), Ibn Mugì (m. 459/1067) y al-Ŷazirī (m. 585/1189) ${ }^{8}$. Tanto en los comentarios jurídicos de estos autores al texto de los formularios como en otras discusiones de tipo legal se da por supuesta la utilización de la tadmiya y su valor documental en el proceso de investigación del delito.

¿A qué se refiere, pues, al-Burzulī, cuando vincula el abandono de esa práctica en el Túnez de su tiempo con una tradición andalusí que se remontaría a al-Lu'lu'î?

Abū Bakr Aḥmad b. 'Abd Allāh b. Aḥmad (o Muhammad b. Aḥmad) al-Umawī al-Lu'lu'ī (m. 348, 350 o 351/959-963) es un personaje identificable en la literatura biográfica andalusí ${ }^{9}$, que lo cataloga como sabio polifacético, entendido en lengua, poesía y hadìt, experto muftí y que, según Ibn al-Faraḍī, conocía a la perfección el $m a \underline{d} h a b$ de Mālik ${ }^{10}$. Pero es en el texto que le dedica el qạ̄̂i 'Iyāọ donde se encuentra, junto a estos y otros detalles típicos de la descripción biográfica de los sabios andalusíes, un largo relato que explica la «cuestión»a la que se refiere al-Burzulī, y que presenta un interés in-

\footnotetext{
${ }^{6}$ Arévalo, R., Derecho penal islámico, 19.

7 Benaboud, M. y Bensbaa, M., «Privatisation and Inheritance in Andalusian Documents during the Period of the Murābițūn», Al-Qanțara, XIV (1993), 259-74, esp. 271 (texto árabe). Se reproduce esta cuestión en al-Wanšarīīi, $A l-M i$ 'yār al-mu 'rib, ed. Haŷŷî, M., Rabat, 1981, II, 289 y en al-Burzulì, Ŷāmi 'masā'il al-ahkām, VI, 92-3, en ambos casos omitiendo la identificación onomástica de los protagonistas.

${ }^{8} \mathrm{Ibn}$ al-'Atțār, Kitäb al-watãa 'iq wa-l-siŷillāt, ed. Chalmeta, P. y Corriente, F., Madrid, 1983, 290-300 (versión castellana en Chalmeta, P., «Acerca de los delitos de sangre en al-Andalus durante el Califato», reproducido en Ibn al-'Attār, Formulario notarial y judicial andalusí, trad. y estudio de Chalmeta, P. y Marugán, M., Madrid, 2000, 496-507); Ibn Mugiț Al-Muqni' fí 'ilm al-šurūt, ed. Aguirre Sádaba, F. J., Madrid, 1994, 361-64; al-Ŷazīī, al-Maqșad al-maḥmūd fì taljịs al-'uqūd, ed. Ferreras, A., Madrid, 1998, 442-44.

9 Véase la relación de fuentes que se ocupan de él en Ávila, M. L., La sociedad hispanomusulmana al final del califato, Madrid, 1985, n. 209.

${ }^{10}$ Ibn al-Faradị, Ta'rỉj 'ulamã ' al-Andalus, ed. Codera, F., Madrid, 1891-92, n. ${ }^{\circ} 122$.
} 
dudable, tanto para la tradición jurídica a la que alude el alfaquí tunecino como para la historia social y, en último término, para comprender hasta qué punto las experiencias personales, propias o ajenas, formaron parte de la reflexión de los juristas. Doy a continuación un resumen detallado de ese texto ${ }^{11}$.

La causa de que, al final de su vida, al-Lu'lu'ì dejara de tener en cuenta la tadmiya y no la considerase válida radicaba en un suceso de su vida personal. Al-Lu'lu'ī tenía un vecino, hombre astuto e inteligente, dueño de una finca que el alfaquí cordobés deseaba ardientemente adquirir, para completar sus propias posesiones rurales. A pesar de lo mucho que al-Lu'lu'ì le rogaba e insistía en la venta, su vecino se negaba siempre a satisfacer sus deseos. En esto, cayó enfermo y al-Lu'lu'ĩ fue a visitarlo. Como el vecino le manifestase su alegría y agradecimiento por su presencia, creyó al-Lu'lu'ī que podía ser aquél momento propicio para renovar su pretensión de compra. El enfermo se mostró de acuerdo y propuso a al-Lu'lu'ĩ que trajese a los alfaquíes necesarios para atestiguar el asunto, rechazando igualmente la oferta de al-Lu'lu'ì de volver con el dinero que tuviese a mano para formalizar la compraventa.

Todo parecía, pues, dispuesto para que al-Lu'lu'ī cumpliese por fin sus deseos. Volvió, en efecto, con un grupo de alfaquíes, encontrando al vecino enfermo en estado de gran debilidad. Pero, cuando al-Lu'lu'î le pidió que diera su testimonio sobre la compraventa, ante su asombro y el de sus acompañantes, lo que dijo fue muy diferente: "Os pongo como testigos de que el alfaquí al-Lu'lu'ī me ha atacado deliberadamente y con intención de matarme; que él es el responsable del derramamiento de mi sangre y que si me muero, pido que se le reclame el talión, pues él es el responsable de mi sangre y vosotros garantes de su cumplimiento»" ${ }^{12}$.

De nada sirvieron los esfuerzos del acusado y los demás alfaquíes: el enfermó no se retractó de su testimonio. Al-Lu'lu'ī, finalmente, pidió a sus colegas que le dejaran solo con su vecino, al que reprochó amargamente su actuación y pidió explicaciones de lo que estaba sucediendo. El enfermo, a su vez, le recriminó que su visita, que él había tomado como prueba de afecto y buena vecindad, no tuviera otro fin que apoderarse de su finca, de manera que en realidad,

${ }^{11}$ Qāḍi 'Iyāḍ, Tartīb al-madārik, ed. A'rāb, S.A., VI, Rabat, 1981, 115-17.

12 Ibidem, 116. 
al-Lu'lu'ī había obrado impulsado por la codicia y los malos deseos. De ello se arrepentía ahora, afirmó al-Lu'lu'ī, rogando al otro que le exonerase de la tadmiya que había pronunciado ante testigos. El astuto vecino accedió, a condición sin embargo de que al-Lu'lu'ì jurase que ni durante su vida ni tras su muerte intentaría comprar la susodicha finca y que se abstendría, incluso, de aceptarla si llegado el caso le fuera a corresponder como herencia. Llegados por fin a un acuerdo, entraron de nuevo los alfaquíes testigos, a quienes el enfermo testimonió que había perdonado a al-Lu'lu'ī, por lo que decaía en su derecho de reclamarle el precio de su sangre. Se negó, no obstante, a reconocer que antes había mentido, como pretendía al-Lu'lu'î, al que dijo: «Ésta es la verdad. Si te contentas con mi perdón, bien, y si no, me reafirmo en lo que dije contra ti. No me desmiento, puesto que tú querías matarme» ${ }^{13}$. No tuvo más remedio al-Lu'lu'í que aceptar la situación, que le mostró los peligros a que se exponía un hombre inocente ante una acusación de esta clase, renunciando desde entonces a dar respaldo jurídico a la tadmiya. Por sí sola, la inculpación no era, desde luego, suficiente, pero sí ponía en marcha un proceso en el que se podía producir la prisión del inculpado en tanto se aclaraban los hechos.

El recuerdo de esta curiosa historia llegó, como se ha visto, hasta tiempos de al-Burzulī, que la acepta como tradición de algunos juristas andalusíes. Que no se trataba únicamente de una opción personal, adoptada por al-Lu'lu'ì como consecuencia de su desagradable experiencia, lo demuestra un caso que sucedió en Córdoba pocos años después de su muerte. Un tal Muhammad b. 'Abd Allāh inculpó ante testigos a Aḥmad b. 'Umar b. Abī 'Uțān de haberle causado heridas en la cabeza y en el brazo de forma intencionada, por lo que declaraba que Muhammad debía someterse al talión en caso de su muerte. Realizó esta inculpación (tadmiya) estando en su lecho de herido y en posesión de sus facultades mentales, imputación que fue rechazada por el demandado. Ambas declaraciones, debidamente testificadas, se hicieron el 16 de ŷumādà II de 359/26 de abril de $970{ }^{14}$.

13 Ibidem, 117.

${ }^{14}$ El relato más extenso y detallado de todo este asunto, en al-Wanšarīsī, $A l-M i$ ‘ yār al-mu'rib, II, 315-17. Una versión más breve -y en ocasiones algo confusa-, en al-Burzulī, Ŷämi ' masā'il al-ahkām, VI, 65-66. Cf. un resumen de los hechos (sin los dictámenes jurídicos finales) en Lagardère, V., Histoire et société dans l'Occident musulman au Moyen Âge, Madrid, 1995, 55-56. 
Sobre el asunto fueron consultados alfaquíes andalusíes (sin mayor precisión), cuya respuesta se acogía a la doctrina mālikí: si se verificaba que las heridas del reclamante eran graves y que no se las podía haber hecho él mismo, el acusado debía permanecer en la cárcel hasta que se dilucidara la verdad de los hechos, o hasta que el acusador muriese y se procediese en consecuencia. Hubo, sin embargo, una opinión divergente: la de 'Abd al-Raḥmān b. Aḥmad b. Baqī 15, quien afirmó que se abstenía de dictaminar en lo referente a la tadmiya, siguiendo en esto la posición (madhab) de su padre y de su abuelo.

Volveré en seguida sobre esta opinión divergente, para continuar ahora con el desarrollo de los hechos. Se produce en ese momento la intervención directa del califa al-Hakam II, que ordena a Ibn Hudayr ${ }^{16}$ buscar y encarcelar al fatà del acusado, puesto que había sido informado de su participación en el asunto. El fatà apoyó la declaración de su señor. Entonces ordenó el califa que se enviaran a casa del herido testigos honorables ('udūl) y médicos expertos. Éstos debían examinar las heridas y emitir un diagnóstico sobre ellas; los testigos debían escuchar la declaración del herido y asegurarse de si persistía en su primera inculpación o la modificaba. Si se daba el primero de estos casos, el herido debía hacer un juramento cincuentenario ${ }^{17}$ sobre la autoría de Ibn Abī 'Uțmān y su intencionalidad de muerte. Una vez cumplidos estos requisitos, Ibn Hudayr debía con-

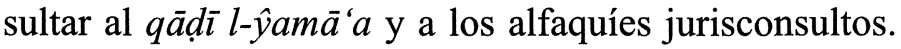

En cumplimiento de estas órdenes, los médicos atestiguaron que las heridas de Muhammad b. 'Abd Allāh no eran de suma gravedad y podían curarse si se sometían al tratamiento adecuado. Por su parte, los testigos hicieron ver al herido la importancia de su declaración jurada, que debía hacerse, si le era posible, en la mezquita, y le amonestaron sobre sus consecuencias. En vista de lo cual, Muhammad b. 'Abd Allāh hizo una nueva declaración, en la que afirmaba que la herida de la cabeza se la había hecho el fatà de Ibn Abī 'Uțmān, Tammām, mientras que confirmó que la del brazo, hecha con intencionalidad y no por accidente, sí era obra de Ibn Abì 'Uțān.

15 Tanto en al-Wanšarīīi como en al-Burzulī: 'Abd al-Rahman b. Baqī b. Majlad.

16 Véase más adelante la posible identificación de este personaje.

17 En el texto se utiliza el término general de yamin, aunque este juramento se llama comúnmente qasāma. Véase el apartado 2 de este trabajo. 
Sobre todo el asunto opinaron a continuación el juez mayor de Córdoba y los miembros de su consejo consultor. En primer lugar, en opinión del qāộ̉ Muhammad b. Ishạāq ${ }^{18}$, en ausencia de pruebas concluyentes no se debía encarcelar, como consecuencia de una tadmiya, a quien tuviera una reputación que hiciera poco probable la comisión de un delito de sangre. Por tanto, el $q \bar{a} a \grave{l} \overline{\text { se }}$ pronunciaba en favor de la excarcelación de Ibn Abī 'Uțān, de quien no se conocían hechos semejantes, y lo mismo de su fatà, si se trataba de persona de buenas costumbres.

Los jurisconsultos compartieron la opinión del qāẹī, aunque difirieron en las razones por las que Tammām también debía ser excarcelado. Según Ahmad b. al-Walīd ${ }^{19}$, la liberación del fatà se debía a las alteraciones habidas en la inculpación del herido; según al-Qāsim b. Jalaf ${ }^{20}$, no se le debía mantener en prisión ni aun cuando fuera de reputación dudosa. Aunque este extremo no se menciona expresamente en el texto, la unanimidad de opinión entre el qäại y sus jurisconsultos hace suponer que tanto el inculpado como su servidor fueron liberados de prisión.

Volvamos al inicio de la cuestión, en donde se menciona que, consultados al respecto un grupo de alfaquíes - a los que no se nombra- 'Abd al-Raḥmān b. Aḥmad b. Baqī se distinguió del resto afirmando que se abstenía de pronunciarse respecto a la tadmiya,

18 Así aparece nombrado en al-Wanšarīsī, al-Mi 'yār al-mu'rib, II, 316. Se trata de Abū Bakr Muḥammad b. Isḥāq b. Mundir b. Ibrāhīm b. Muhammad b. al-Salīm b. Abī 'Ikrima Ŷa'far b. Yazīd b. 'Abd Allāh (m. 367/977-78), conocido como Ibn al-Salīm, nombrado qā $\bar{d} \bar{i} l-\hat{y} a m \bar{a}$ ' $a$ por al-Hakam II en 355/966; permaneció en este cargo hasta después de la muerte del califa. Cf. Marín, M., «Altos funcionarios para el califa: jueces y otros cargos de la administración de 'Abd al-Rahmān III», Cuadernos de Madinat al-Zahrä', 5 (2004), 91-105, esp. 100-1.

${ }_{19}$ Así aparece tanto en al-Wanšarīīi (al-Mi yãr al-mu'rib, II, 317) como en al-Burzulì ( $\hat{Y} a \bar{a} m i$ ' masā' 'il al-ahkām, VII, 66). Debe tratarse de 'Ubayd Allāh b. al-Walìd b. Muhammad b. Yūsuf (m. 378/988-89), uno de los muftíes más importantes durante el reinado de al-Hakam II (Ávila, M. L., La sociedad hispanomusulmana, n. ${ }^{\circ} 1022$ ).

${ }^{20}$ El jurisconsulto al-Qāsim b. Jalaf b. Fatḥ b. 'Abd Allāh b. Ŷubayr al-Ŷubayrī (m. 371/981-82 o 378/988-89) era muy estimado por al-Hakam II, quien le hizo residir en Madīnat al-Zahrā'. Tras la muerte del califa, estuvo implicado en la conjura de 'Abd al-Malik b. Mundir b. Sa'īd contra Hišām II, en la que participaron otros ulemas. 'Abd al-Malik fue condenado a muerte y al-Qāsim b. Jalaf y otros ulemas acusados fueron encarcelados. Al-Qāsim no salió de la cárcel, donde permaneció unos diez años, hasta morir en ella (Qādị 'Iyād, Tartīb al-madnārik, VII, ed. A'rāb, S. A., Rabat, 1982, 6-7. Otras referencias biográficas, en Ávila, M. L., La sociedad hispanomusulmana, n. ${ }^{\circ}$ 895. Sobre la conjura de 'Abd al-Malik b. Mundir b. Sa'īd, que se produjo en 368/979, cf. Fierro, M., La heterodoxia en al-Andalus durante el periodo omeya, 166). 
siguiendo la postura de su padre y de su abuelo. 'Abd al-Rahmmān, en efecto, era nieto de Baqī b. Majlad (m. 276/889), el muy conocido tradicionista, e hijo de Ahmad, no menos famoso como qāại l-ŷama' 'a de Córdoba, cargo que ocupó desde 314/926-27 hasta su muerte en 324/935-36 ${ }^{21}$. Por su parte, 'Abd al-Raḥmān b. Baqi parece haberse ganado el reconocimiento de su saber y, sobre todo, de su posición como depositario de la tradición familiar, aunque a diferencia de su padre, no ocupó ningún cargo en la administración jurídico-religiosa; antes bien, rechazó la dirección de la oración en la mezquita mayor de Córdoba, la cual tuvo que asumir el qãdī Muḥammad b. Isḥāq Ibn al-Salīm, mencionado más arriba. 'Abd al-Raḥmān b. Aḥmad b. Baqī murió en 366/976 22 .

$\mathrm{Al}$ abstenerse de opinar sobre la tadmiya, Ibn Baqī seguía no sólo una tradición familiar, sino una corriente intelectual en la que predominaban las tendencias šãfi'íes, que habían influido fuertemente a Baqī b. Majlad ${ }^{23}$. Y, efectivamente, la escuela šāfi'í nunca consideró la tadmiya como una de las categorías de la «sospecha fundamentada» (lawt) de haberse cometido un delito ${ }^{24}$, y de ahí que el alfaquí Ibn Baqī se negara a pronunciarse al respecto. Huellas anteriores de esta vinculación entre el rechazo a la tadmiya y la escuela šăfíí se encuentran en una consulta en la que participó Yahyà b. 'Ubayd Allāh b. Yahyà (m. 303/915) ${ }^{25}$. Al comentar la postura negativa de este nieto de Yahyà $\mathrm{b}$. Yahyà respecto $\mathrm{a}$ la tadmiya, Ibn Sahl la explica porque «en vida de su padre, aceptó durante algún tiempo el fiqh de Muhammad b. Idrīs al-Šāfi'ì y otros mālikíes que lo siguieron, aunque había refutado a al-Šāfi‘ ‘ĩ en muchas de sus cuestiones jurídicas» ${ }^{26}$.

\footnotetext{
${ }^{21}$ Marín, M., "Altos funcionarios para el califa», 98-99. Sobre otros descendientes de Baqī, Marín, M., «Baqī b. Majlad y la introducción del estudio del hadịt en al-Andalus», Al-Qantara, I (1980), 165-208, esp. 172-76.

${ }^{22}$ Ávila, M. L., La sociedad hispanomusulmana, n. ${ }^{\circ}$ 153; Marín, M. «Baqī b. Majlad», 174-75.

${ }^{23}$ Sobre este punto y sobre la huella de al-Šāfi'ī en al-Andalus, cf. Fierro, M., "La política religiosa de 'Abd al-Rahmān III", Al-Qanțara, XXV (2004), 119-56.

${ }^{24}$ Coulson, N. J., A History of Islamic Law, Edimburgo, 1978, 93-94.

${ }_{25}$ Marín, M., «Una familia de ulemas cordobeses: los Banū Abī 'İsà», Al-Qanțara, VI (1985), 291-320, esp. 302.

26 Ibn Sahl, Dīwān al-aḥkām al-kubrà, ed. al-Nu'aymī, R., al-Riyāḍ, 1997, II, 1278-79. Esta información sobre las tendencias šãfi'íes de Yahyà b. 'Ubayd Allāh no aparece en las breves biografias que se le dedican en los diccionarios biográficos (cf. Marín, M., «Nómina de sabios de al-Andalus (93-350/711-961)», EOBA, I, Madrid, 1988, n. $\left.{ }^{\circ} 1560\right)$.
} 
En la larga biografía que el qāẹi 'Iyāḍ consagró a Aḥmad b. Baqī, con muchos relatos sobre su actuación como juez, no aparece ningún ejemplo relacionado con la inculpación de asesinato por este procedimiento, pero el testimonio de su hijo a este respecto parece verosímil. Tendríamos, por tanto, en la divergencia expresada por Ibn Baqī, la pervivencia de una corriente intelectual que tuvo un papel significativo aunque minoritario bajo el reinado de 'Abd al-Raḥmān III, al menos hasta la ejecución, en 338/950 ó 339/951, de su hijo 'Abd Allāh, šãfi'í, acusado de conspiración contra el califa ${ }^{27}$.

Es sabido que este 'Abd Allāh y su hermano al-Hakam - el futuro califa - se enfrentaron en vida de su padre, creando a su alrededor «partidos» de ulemas ${ }^{28}$ que les apoyaban y que hasta cierto punto reflejaban diferencias doctrinales (šāfi'ismo, mālikismo), aunque se tratase, principalmente, de una lucha por el poder político. En ese marco se entiende quizá mejor la decidida intervención de al-Hakam, ya califa, cuando en 359/970, 'Abd al-Raḥmān b. Aḥmad b. Baqī desdeña pronunciarse sobre la tadmiya, reivindicando la tradición intelectual del šãfi'ismo de su padre y su abuelo.

Como se ha visto más arriba, el califa organiza la investigación criminal del caso y pone a su frente a Ibn Hudayr. Se trata, muy probablemente, de un miembro de la poderosa familia de los Banū Hudayr ${ }^{29}$, que ocuparon diversos cargos en la administración omeya. En este caso concreto, podría tratarse de 'Abd al-Raḥmān b. Mūsà $b$. Muhammad b. Sa 'îd b. Mūsà (m. 369/979) de quien se sabe que fue sāhib al-mazālim en 361/972 ${ }^{30}$. Al hacer este encargo a Ibn Ḥudayr, al-Ḥakam sigue una práctica usual en al-Andalus; conviene recordar que es el wäli l-madina que aparece en el caso evocado al inicio de estas páginas, Muḥammad b. al-Salīm, quien convoca a los miembros del consejo consultivo del $q \bar{a} d \underline{\imath} \bar{l}$ por orden del emir, para tratar del asunto del sobrino de 'Aŷab ${ }^{31}$. Lo que sí llama la atención en la intervención de al-Ḥakam II es el detalle con el que dispone el

${ }^{27}$ Fierro, M., «La política religiosa de 'Abd al-Raḥmān III», 145-47.

${ }_{28}$ Marín, M., «Altos funcionarios para el califa», 95-96.

29 Manzano Moreno, E., «El círculo de poder de los califas omeyas de Córdoba», Cuadernos de Madinat al-Zahrā'; 5 (2004), 9-29, da una lista de los miembros de los Banū Hudayr documentados en época califal.

30 Meouak, M., Pouvoir souverain, administration centrale et élites politique dans l'Espagne umayyade, Helsinki, 1999, 127 (n. $\left.{ }^{\circ} 14\right)$.

${ }^{31}$ Cf. supra, nota 2. 
procedimiento que se ha de seguir, instruyendo a Ibn Hudayr sobre todos los pasos que deben darse, requiriendo la presencia de testigos honorables y haciendo hincapié en que el acusador tiene que pronunciar un juramento cincuentenario sobre su aserto. El califa aparece, así, como el supremo conocedor de las técnicas legales y de los fundamentos jurídicos de la investigación; aunque una vez concluida ésta, Ibn Hudayr debe presentar los datos al qāại $l-\hat{y} a m \bar{a}$ ' $a$ y a los jurisconsultos, la dirección que estos alfaquíes iban a tomar estaba prácticamente señalada mediante la actuación del califa. Los autores mālikíes que recogieron, con posterioridad, este caso, no dudan en tomarlo como ocasión para alabar los conocimientos de al-Hakam II, de quien dicen «no hubo entre los Banū Umayya de al-Andalus nadie más entregado que él al estudio de las ciencias ni con más conocimientos que él con los ulemas, dedicándose a esto y descollando en ello» ${ }^{32}$.

Por otro lado, en la intervención de al-Hakam II en este asunto pudieron jugar otros factores. Lo primero que ordena a Ibn Hudayr, en efecto, es que busque y encarcele a un fatà del acusado, "puesto que había sido informado (id ittasala bi-hi) de que el herido sostenía también que el fatà le había causado alguna de las heridas» ${ }^{33}$. Es la primera aparición de este fatà en el texto de la consulta, y lo hace de forma que parece que el califa estaba siguiendo el asunto muy de cerca y tenía sus propias fuentes de información. Los dos personajes implicados, Muhammad b. 'Abd Allāh y Ahmad b. 'Umar b. Abī 'Uțmān, parecen haber disfrutado de cierta posición, al menos el segundo, que era dueño de un esclavo ${ }^{34}$. Quizá sea esta posición la que explique la intervención del califa, aunque saber cuál era su relación con al-Hakam, si es que existió, es imposible.

De los dos casos examinados sobre la consideración de la tadmiya como elemento fundamentador de una sospecha de autoría criminal, VI, 66.

32 Al-Wanšarīisī, Al-Mi 'yār al-mu 'rib, II, 317; al-Burzulī, Ŷāmi ' masā'il al-ahkām,

33 Al-Wanšarīsī, Al-Mi 'yār al-mu'rib, II, 316.

34 Aunque el término fatà es polisémico (cf. De la Puente, C., «Sin linaje, sin alcurnia, sin hogar: eunucos en al-Andalus en época omeya» en Identidades marginales (EOBA, XIII), ed. De la Puente, C., 147-93) y Tammām nunca es calificado expresamente de «esclavo», si hay referencia en el texto de la cuestión a su dueño (mawlà). Las respuestas de los alfaquíes apuntan también en esa dirección, al declarar prácticamente que la responsabilidad de los hechos no le corresponde. 
se deduce que las divergencias en torno a ese punto no eran sólo las que se planteaban entre corrientes jurídicas (mālikismo y šãfi 'ismo). Desde época temprana se manifestó la conveniencia de atemperar las consecuencias de una imputación semejante y buscar pruebas convincentes que la apoyaran. Entre los fragmentos conservados del Kitāb al-Wädiha de 'Abd al-Malik b. Habīb (m. 238/852) se reproducen dos inculpaciones de delitos de sangre hechas por las personas agredidas - aunque sin recibir el término técnico de tadmiya. La primera de ellas se desestima por tratarse de la acusación de un esclavo contra un hombre libre (aunque éste deberá hacer un juramento cincuentenario); en la segunda, al constatarse que existía entre acusador y acusado una enemistad manifiesta, se requiere la existencia de una sospecha clara y una acusación fundada ${ }^{35}$. Los propios mālikíes disintieron en cuanto a las consecuencias a las que debía llevar la aceptación de la tadmi$y a$, como asegura el tardío recopilador al-Burzulī, recogiendo opiniones divergentes de Ibn al-Qāsim e Ibn Kināna ${ }^{36}$. Se discutió, sobre todo, si había que encarcelar al acusado en vida del acusador o esperar a su muerte, y qué clase de pruebas complementarias eran necesarias. Además, en el procedimiento establecido tenían un papel decisivo, como se ha visto, la reputación de las partes implicadas en el delito y, como prueba que confirme la grave sospecha suscitada por la tadmiya, el juramento cincuentenario (qasāma).

\section{Los cincuenta juramentos (qasāma) y la investigación criminal}

Hemos visto que la tadmiya constituía un primer paso en la configuración de la «sospecha fundamentada» (lawt), que también podía crearse por el testimonio único de un testigo honorable o por el testimonio de un grupo de personas que no entrasen en esa categoría

35 'Abd al-Malik b. Habīb, Kitāb al-Wādiha (Tratado jurídico). Fragmentos extraídos del Muntajab al-ạ̣kām de Ibn Abi Zamanin, ed. Arcas Campoy, M., Madrid, 2002, 114-5/trad.116-7. Estos textos ya fueron presentados por Arcas Campoy, M., «Actos delictivos y acción penal en la Wãdiḩa de Ibn Habỉb», BAEO XXIV (1998), 139-46. Sobre la obra jurídica de Ibn Habīb y, en general, la producción y circulación de textos jurídicos en el $\mathrm{s}$. III/IX en al-Andalus, cf. Fernández Félix, A., Cuestiones legales del islam temprano: la 'Utbiyya y el proceso de formación de la sociedad islámica andalusi, Madrid, 2003, 314-32.

36 Al-Burzulī, Ŷămi ' masā'il al-aḥkām, VI, 59. Véase también Ibn Rušd al-Ŷadd, Al-Bayān wa-l-taḥsill, Beirut, 1988, XV, 524-25. 
(lafíf ${ }^{37}$. Una vez aceptada la grave sospecha del delito, se procedía al «juramento cincuentenario» (qasāma), que como se observó en las actuaciones ordenadas por al-Hakam II, debía pronunciarse en la mezquita ${ }^{38}$.

Los ejemplos de puesta en práctica de la qasāma no escasean en la literatura jurídica andalusí. El caso que voy a presentar a continuación ha sido seleccionado en este contexto por la riqueza de detalles que contiene y porque, como en la cuestión anteriormente tratada, está bien documentado históricamente. Nos permite, además, seguir los pasos de una investigación sobre el terreno tras haberse cometido un crimen y reconstruir todo un entramado de relaciones personales, económicas y sociales en el entorno rural andalusí.

Si las circunstancias del delito y de las personas implicadas en él nos son tan bien conocidas, ello se debe, muy probablemente, a que su protagonista principal, muerto violentamente, era hermano de un conocido ulema valenciano, Abū Baḥr Sufyān b. al-'Āṣī al-Asadī (440-520/1048-1126) ${ }^{39}$. Educado en Valencia, Abū Bahr era originario del hișn de Murbițar/Murbātị (Murviedro), lugar donde precisamente se desarrollaron los hechos y que parece ser solar de la familia, en cuya región eran propietarios rurales ${ }^{40}$. Abū Bahr desarrolló una carrera clá-

37 Arévalo, R., Derecho penal islámico, 18-19.

38 Se trata, según Ibn Rušd, de un juramento que ha de hacerse de pie frente a la alquibla, al término de la oración de la tarde y en viernes. El padre del hombre asesinado sobre el que trata la cuestión planteada a Ibn Rušd debía pronunciar 50 veces la siguiente fórmula: «Por Dios, el único que es Dios, conocedor de lo oculto y de la fe, ha matado éste -señalándolo- a mi hijo Fulano, por las heridas que le infligió y de las que ha muerto, de forma intencionada y alevosa» (al-Wanšarīsī, al-Mi 'yār al-mu'rib, II, 303). El padre de este hombre actúa en su calidad de wali l-dam (pl. awliya $\bar{a}^{\prime}$ al-dam), es decir de pariente agnático que puede reclamar compensación por la sangre derramada. Cf. Peters, R., «Murder in Khaybar. Some Thoughts on the Origins of the qasäma Procedure in Islamic Law», Islamic Law and Society, 9 (2002), 132-65.

39 Ávila, M. L. y Marín, M:, «Nómina de sabios de al-Andalus (430-520/10381126)», EOBA, VII, Madrid, $1995,55-189$, n. $^{\circ} 628$.

${ }^{40}$ Sobre Murviedro (actual Sagunto) en época andalusí, cf. Pavón Maldonado, B., «Sagunto: villa medieval de raíz islámica. Contribución al estudio de las ciudades hispanomusulmanas», Al-Andalus XLIII (1978), 181-99; Aguiló Lúcia, P., «El sistema defensivo del Camp de Morvedre», Actas del I Congreso de Arqueología Medieval Española, Zaragoza, 1986, III, 347-55 y Franco Sánchez, F., «Estudio comparativo del urbanismo islámico de seis poblaciones de la Vía Augusta: Sagunto/Xàtiva/Orihuela y Ontinyent/Bocairent/Beneixama», Simposio Internacional sobre la ciudad islámica, Zaragoza, 1991, 353-75. Se ocupan de problemas de toponimia Bramon, D. y Lluch Bramon, R., «Segó (Camp de Morvedre) a les fonts àrabs i cristianes medievals», en id., Mots remots. Setze estudis d'història i toponimia catalana, Girona, 2002, 123-33. 
sica de ulema, estudiando con maestros reputados de su tiempo y alcanzando una gran consideración en los ambientes de los estudiosos de su tiempo. Tras la conquista cristiana de Valencia, Abū Bahrr se trasladó al norte de África, pero volvió luego a al-Andalus y se estableció en Córdoba (allí lo encontró el qā dī 'Iyāẹ en 507/1113- 14) ${ }^{41}$, donde residió hasta su muerte. Como ocurre en un gran porcentaje de las biografías de los ulemas, nada se dice en las de Abū Baḥr sobre sus medios de vida; gracias al caso que veremos a continuación, se sabe que pertenecía a una familia acomodada de propietarios y comerciantes.

Del hermano de Abū Baḥr se conocen una serie de datos biográficos contenidos en la consulta que él mismo hizo a Ibn Rušd a propósito de su muerte ${ }^{42}$. En la introducción al texto de la consulta se afirma que eran ambos hermanos uterinos y que Muhammad b. al-'Āṣì, que así se llamaba el muerto, había sido asesinado en Murviedro (Murbittar), «una de las antiguas fortalezas del oriente de al-Andalus», en dū 1-hiŷŷa del año 510, pocos días después de la fiesta de los sacrificios [ 15 de abril de 1117] ${ }^{43}$. A continuación, y ya en el propio texto de la consulta, se describe de este modo a Muhammad b. al-'Āṣī:

«[Era] uno de los notables ( $a$ ' yān) de su lugar de residencia, donde poseía fincas y que, después de cumplir con el precepto de la peregrinación, se había dedicado a su cultivo, confiando en lo que de ellas podía extraer y habiéndose conformado con el estado de soltería sin haber formado familia. No tenía otro objetivo que la mejora de sus tierras y el cuidado de lo que ellas producían. Hacía préstamos ( $k a \bar{n} a$ yuqāriḍ) sobre el excedente de sus ingresos a quienes comerciaban con ese dinero; del mismo modo, concedía anticipos a sus vecinos en momentos de necesidad, con avales o sin ellos. Tanto se prodigó en estas acciones que su fama se divulgó en el país a causa de su holgada situación y abundancia de posibles» ${ }^{44}$.

41 'Iyāḍ, al-Gunya, ed. Ŷarrār, M., Beirut, 1982, 37.

42 Ibn Rušd al-Ŷadd, Fatāwà, ed. al-Talīlī, M.T, Beirut, 1987, II, 864-71; Masā’ il, ed. al-Tî̀kānī; M.Ḥ, Casablanca, 1992, II, 772-79; al-Wanšarīsì, al-Mi 'yār al-mu 'rib, II, 308-12; al-Burzulī, Yãmi' masã 'il al-aḥkām, VI, 62-64. Sigo de preferencia la edición de Ibn Rušd de al-Talīli [sobre las diferencias entre las dos ediciones, cf. la reseña de Serrano, D., Al-Qantara, XV (1994), 531-34].

${ }_{43}$ Sólo en la edición de al-Talīlī se da la lectura correcta: qatl aji-hi šaqĩqi-hi $M u-$ hammad bi-Murbịtar min husūun al-šarq al-'atīqa (Fatāwà, II, 864), mientras que en Masā'il (II, 772, ed. al-Tiŷkānī) se lee: qatl aji-hi šaqiqqi-hi Muhammad b. Marbāțir, etc.; en al-Wanšarīsĩ: Muhammad b. Bätirir. Al-Burzulī prescinde de referencias onomásticas.

${ }^{44}$ Ibn Rušd, Fatāwà, II, 865. 
De este retrato personal, en el que destaca - junto a la opción personal por el celibato, poco frecuente de no ser, y no siempre, entre ascetas y hombres de religión ${ }^{45}$ - la red de relaciones económicas establecidas entre el gran propietario rural y los habitantes de la región, se pasa, en la consulta a Ibn Rušd, a una descripción de la residencia y forma de vida de Muhammad b. al-'Āṣi:

"Vivía este hombre en una de sus casas $(d \bar{a} r)$, que tenía un aposento (huŷra) con un sobrado ('illiya a) ${ }^{46}$ alto, al que se llegaba por una casa exterior, comunicada por una puerta que daba entrada a la casa tras la cual estaba el aposento mencionado. En los apartamentos (buyūt) de esta casa exterior comunicada por la puerta residían hombres y mujeres musulmanes de buena reputación que eran demasiado pobres para pagar un alquiler, en tanto que él vivía solo en su aposento» ${ }^{47}$.

Las excavaciones arqueológicas en la región valenciana han sacado a la luz plantas de casas de tipología cercana a la aquí descrita ${ }^{48}$, aunque corresponde a los especialistas en esa materia el interpretar un texto que sin duda no está dejando al azar ningún aspecto de la descripción, que es fundamental, como ahora se verá, para la reconstrucción del asesinato de Muhammad. Lo que vemos en esa imagen, en todo caso, es la residencia de un hombre acomodado, amplia y compleja, hasta el punto de que se divide en dos partes claramente diferenciadas: la casa exterior (barrāniya), que comprende habitaciones y apartamentos (buyūt) donde se alojan familias de escasos medios, acogidos a la generosidad del dueño, y la casa interior, en la que éste mantiene su privacidad en sus propios aposentos. Como era usual en la casa andalusí, al menos en las ciudades, esta casa interior disponía de un sobrado o almacería ${ }^{49}$. La casa, como se dice más adelante en la consulta, estaba situada en la ladera del monte de la alcazaba de Murviedro, por lo cual las paredes de los aposentos interiores, situa-

45 Véanse los casos citados en Marín, M., Mujeres en al-Ándalus, 398, nota 14.

${ }^{46}$ Corriente, F., A Dictionary of Andalusi Arabic, Leiden, 1997, s.v. («belvedere»).

47 Ibn Rušd, Fatāwà, II, 865.

48 Bazzana, A., «Maisons rurales du shark al-Andalus. Essai de typologie», La casa hispano-musulmana. Aportaciones de la arqueologia, Granada, 1990, 247-67, esp. 263

49 Cf. el trabajo clásico de Torres Balbás, L., "Algunos aspectos de la casa hispanomusulmana: almacerías, algorfas y saledizos», Al-Andalus, XV (1950), 179-91 y más recientemente, Navarro Palazón, J. y Jiménez Castillo, P., «Plantas altas en edificios andalusíes: la aportación de la arqueología», Arqueología Medieval, 4 (1996), 107-37. 
dos en la parte más elevada de la residencia, no eran muy altas (y se podían escalar fácilmente, se añade en el texto) ${ }^{50}$.

Una vez especificada la topografía del lugar del crimen, el autor de la consulta procede a dar los antecedentes de tipo personal que considera necesarios para comprender los hechos. Al proceder así está seleccionando datos que inevitablemente conducen a sospechar de una persona en concreto como autor del delito. Se trata de un joven (fatà) de Murviedro, con el que Muhammad había establecido una estrecha relación, hasta el punto de haberle concedido un capital con el que iniciar actividades comerciales. También se ocupaba de cobrar las deudas pendientes con Muhammad b. al-'Āṣi y de las ventas de sus cosechas, todo lo cual hacía necesaria su presencia en la casa de forma continua y «que pernoctase en su casa alguna noche, pasando en solaz y compañía gran parte de la velada nocturna y durmiendo luego en su residencia en esas ocasiones» ${ }^{51}$. La puerta que comunicaba las dos secciones de la casa se cerraba cuando los habitantes de la casa exterior volvían de la última oración del día. $\mathrm{Si}$ el joven amigo de Muhammad b. al-'Āṣī llegaba después de esa hora, le abrían la puerta para que entrase en la casa interior y la volvían a cerrar si salía tras la velada. Una noche el joven entró, como tenía por costumbre; los vecinos cerraron la puerta tras él, pero el joven no volvió a salir.

A partir de ese punto, el autor de la consulta adopta un estilo ya claramente narrativo y reconstruye los hechos tal como debieron de suceder. Da por hecho que el autor del asesinato ha sido el joven, conjurado con otros tales de mala condición, puesto que el crimen no pudo haber sido cometido por una sola persona y, además, había sido visto por vecinos del pueblo en lugares apartados y en actitud que denotaba que estaba planeando algún mal designio. Todos entraron a los aposentos de Muhammad por la parte trasera, la que daba a la ladera del monte y que era de más fácil acceso; sorprendieron al hombre, profundamente dormido, lo maniataron y lo estrangularon. A conti-

50 Sobre la alcazaba de Sagunto y el poblamiento de la ciudad en época andalusí, cf., además de los trabajos citados en la nota 40, Bazzana, A., Maisons d'al-Andalus. Habitat médiéval et structures du peuplement dans l'Espagne orientale, Madrid, 1992, I, 224 y 270-71.

51 Ibn Rušd, Fatāwà, II, 865-66. Parece evidente que pudo haber una relación íntima entre Muhammad b. al-'Āṣī y el joven en cuestión (no hay que olvidar que Muhammad no estaba casado por decisión propia). El texto, como es natural, elude esta cuestión. 
nuación quebrantaron su caja de caudales, en la que guardaba sus dineros y su ropa y se llevaron todo lo que encontraron de valor, saliendo de nuevo por la parte de atrás de la casa.

A la mañana siguiente, los vecinos de la casa exterior observaron que Muhammad b. al-'Āṣi no acudía, como tenía por costumbre, a despertarlos para que los que quisieran fueran con él a rezar la primera oración en la mezquita. Creyéndole dormido, llamaron repetidamente a su puerta sin obtener respuesta, en vista de lo cual llamaron a un pariente suyo, que ante la falta de respuesta tuvo por cierto que había sucedido una desgracia y preguntó quién había pernoctado en la casa. Informado de la llegada del joven, pero de que nadie le había visto salir, este pariente forzó la puerta, ayudado por algunos de los presentes, y entró con ellos, descubriendo el cadáver de Muhammad y las huellas del saqueo. Inmediatamente se dirigieron a la residencia del joven, que encontraron vacía de sus enseres y ropa; el sospechoso se había refugiado en una aldea (qarya) en la que vivía un cuñado suyo, implicado también en el crimen. Para remachar los indicios de criminalidad, se añade en este punto que, antes de que se hubiera advertido el suceso, la hermana del joven, cuyo marido era el otro sospechoso, había llegado antes del amanecer y había dicho a una de las mujeres que vivían en la casa exterior: «si te preguntan por quién ha pernoctado en el aposento ayer, no digas nada de mi hermano y te daré diez meticales» ${ }^{52}$.

El relato de los hechos, tal como aparece en la consulta de Abū Bahr, denota que hubo una investigación del crimen, aunque no se mencione quién la ordenó y quiénes y cómo la llevaron a cabo. Parece lógico suponer que los parientes del muerto acudieran al qā $\bar{d} \grave{l}$ de Murviedro ${ }^{53} \mathrm{o}$ a la autoridad civil (șạhib al-madina), para poner en marcha la averiguación de los hechos. Algunos de los indicios de criminalidad, como la ausencia del joven de su casa, proceden de la rápida

${ }^{52}$ Ibn Rušd, Fatāwà, II, 867.

53 Se conocen los nombres de dos jueces de Murviedro en esta época. 'Abd Allāh b. 'Abd al-Rahmān al-Qudāīi ì murió, precisamente, el mismo año a cuyo último mes corresponden los hechos aquí relatados (510/1117) y es improbable que se pudiera ocupar del caso. Un juez posterior, al-Ḥusayn b. Aḥmad b. Husayn al-'Abdarī, murió en $537 / 1142-43$, no habiendo constancia documental de otros jueces que pudieran ocupar el cargo entre ambos, aunque esto no quiere decir que no los hubiera (tomo los datos sobre los qädies de Murviedro de la Tesis Doctoral de El Hour, R., La organización jurídica de los almorávides en al-Andalus, Universidad Autónoma de Madrid, 1996, II, 576). 
intervención del pariente de Muhammad b. al-‘Āṣī, convencido ya de su culpabilidad; otros parecen derivarse de interrogatorios a los vecinos, tanto los que vivían en la casa exterior como en Murviedro. Como consecuencia de todo ello, la autoridad correspondiente ordenó la detención y encarcelamiento del joven y de su cuñado; como informa el autor de la consulta a Ibn Rušd, en el momento de escribirla ambos estaban en prisión y habían sido azotados para obligarles a revelar la verdad del asunto.

Sin embargo, no lo hicieron, y las pruebas que había contra ellos no eran concluyentes. No había testigos de los hechos, ni el atacado había sobrevivido el tiempo suficiente como para inculpar a sus agresores. De ahí la consulta que se dirige a Ibn Rušd: ¿cuánto tiempo deben permanecer encarcelados?, ¿qué debe hacerse ante la ausencia de una confesión y de pruebas de peso?

Hubo dos respuestas a esta consulta. En la primera, Ibn Rušd afirma que si los hechos son tal como aparecen relatados, corresponde a los awliy $\bar{a}^{\prime}$ al-dam ${ }^{54}$ del difunto hacer el juramento cincuentenario contra aquel de los dos acusados que consideren culpable, haciéndole matar a continuación. Aduce para ello la Tradición Profética, así como la opinión de Mālik sobre las circunstancias en que es necesario el juramento, es decir, cuando no existen pruebas concluyentes y hay dudas sobre la sinceridad de la acusación. Ahora bien, si los awliy $\vec{a}^{\prime}$ al-dam se niegan a pronunciar el juramento o perdonan a los acusados, cada uno de éstos recibirá cien azotes y permanecerán en prisión durante un año ${ }^{55}$.

Disintió de la opinión de Ibn Rušd el jurista cordobés, ya mencionado, Ibn al-Ḥâŷy ${ }^{56}$, para el que era necesario prolongar la prisión de los acusados. Basándose igualmente en la opinión de Mālik, afirma Ibn al-Hâŷŷy que en un caso como el que se le plantea, los sospechosos deben permanecer largo tiempo en la cárcel, sin apresurarse a liberarlos mientras no sea cierta su inocencia. Asimismo, se manifiesta

\footnotetext{
54 Cf. supra, nota 39.

${ }_{55}$ Ibn Rušd, Fatāwà, II, 868. Se trata de una aplicación del castigo discrecional ( $t a$ 'zir) que pone en práctica la autoridad judicial o política si no se produce una acción punitiva por parte de los parientes del fallecido.

56 Quien murió también asesinado, en 529/1134, mientras rezaba en la mezquita mayor de Córdoba. Sobre el autor del crimen y sus motivaciones, cf. Marín, M., «La transmisión del saber en al-Andalus a través del Mu 'ŷam de al-Șadafì), Cuadernos del Cemyr, 5 (1997), 51-72, esp. 65.
} 
Ibn al-Hāŷŷy contrario a que los awliya $\bar{a}^{\prime}$ al-dam del muerto perdonen a los acusados (aunque esta opción les estaba permitida) ${ }^{57}$. Finalmente, si pasado el tiempo no aparecen nuevas pruebas, cada uno de ellos deberá hacer un juramento cincuentenario, al término de su prisión, y según el iŷtihād del qāḍi, de que no mató al asesinado, ni cooperó en modo alguno a su muerte; y otro juramento semejante de que no se apoderó de ninguno de sus bienes. Estos dos juramentos son condición indispensable para la liberación de los acusados.

Los textos presentados en este trabajo son, desde luego, excepcionales. En primer lugar, por su origen; salvo uno - el relativo a al-Lu'lu'ì- proceden todos de compilaciones de carácter legal, en las que no es fácil encontrar precisiones tan detalladas como las que aquí se han ofrecido respecto a la personalidad y las circunstancias de los protagonistas de los casos ${ }^{58}$. Es más, cuando estas precisiones existen, suelen desaparecer en recensiones posteriores del mismo caso, que va perdiendo, conforme lo reproducen sucesivos compiladores, todo lo que no se considera necesario para el estudio de la casuística legal. Así, el más tardío de los autores utilizados aquí, al-Burzulī, suprime casi siempre las referencias onomásticas de las cuestiones que se han tratado. La particularidad de estas cuestiones reside, por tanto, en que es posible considerarlas no sólo como documentos de tipo jurídico, sino también como documentos históricos, en un área para la que no abundan las informaciones en fuentes de otro carácter. Ahora bien, no hay que olvidar que si se conservaron todos estos datos «históricos» fue porque se trataba de personajes distinguidos, ya por ser ulemas prestigiosos, como al-Lu'lu'î, ya por pertenecer a una familia de ulemas, como el hermano de Abū Baḥr b. al-'Āṣī o, finalmente, por representar los valores más apreciados por los ulemas, como al-Hakam II cuando dirige el procedimiento judicial examinado más

57 Véase a este respecto el artículo de Arcas Campoy, M., «Casuística sobre el perdón del talión en el Muntajab al-ậkām de Ibn Abī Zamanīn», en esta misma sección monográfica de Al-Qanțara.

${ }_{58}$ Por otro lado, estas precisiones no siempre pueden aceptarse acríticamente. Un ejemplo servirá para ilustrar esta afirmación. Una cuestión recogida por al-Burzulī (Ŷâmi ' masā'il al-ahkām, VI, 97) se refiere a los habitantes de B.r.šāna, que el editor del texto identifica con Purchena, min hususun al-Andalus. La misma cuestión, en la versión de al-Wanšarīsī (al-Mi ‘yār al-mu 'rib, II, 272) menciona el topónimo, también andalusí, de Qalšāna. Sin embargo, lo más verosímil, puesto que el asunto se plantea ante al-Barqī (que fue qādi de al-Mahdiya), es que se trate de Baršāna, localidad tunecina al sur de Monastir (al-Tiŷānī, Riḥla, Libia-Túnez, 1981, 67). 
arriba. El mensaje de estos textos es, pues, claramente ejemplarizante, y no puede desprenderse de su contenido puramente factual.

Los crímenes de sangre aparecen en estos documentos porque su autoría era problemática y los procedimientos previstos por la normativa legal no eran suficientes para resolver el problema. La irrupción de la violencia en las relaciones personales pone al descubierto discusiones de doctrina y práctica jurídica entre los alfaquíes, pero también los límites de la acción de la justicia ante el delito. Sólo la autoinculpación o la presencia de testigos honorables cuando un crimen se comete garantiza plenamente la identificación del homicida ${ }^{59}$. Así sucedió cuando fue asesinado Ibn al-Ḥâŷŷy ante la congregación de los fieles en la mezquita de Córdoba. Los recursos elaborados por los juristas para compensar la falta de testigos o de confesión del autor del crimen muestran que los indicios o pruebas encontradas durante la investigación - entre ellos, la tadmiya - debían someterse a la corroboración final e indiscutida del juramento cincuentenario ${ }^{60}$.

Al mismo tiempo, la necesidad de averiguar la verdad de los hechos en un crimen saca a la luz contextos familiares y sociales encubiertos en otras circunstancias. No se conocerían las particularidades de la vida doméstica de Abū Marwān al-Ṭubni de no haber sido asesinado y los miembros de su familia, interrogados al respecto. La fingida tadmiya lanzada contra al-Lu'lu'ì revela que se trataba de un propietario de fincas en la campiña cordobesa, ansioso por ampliar sus límites. La biografia de este ulema contiene otro dato interesante respecto a los orígenes de su fortuna: el apellido por el que era conocido se debía a que su padre se dedicaba al comercio de perlas ${ }^{61}$. Otros textos biográficos contienen datos sobre ulemas propietarios de fincas ${ }^{62}$, pero es en la cuestión relativa al asesinato de Muhammad $b$. al-'Āṣi donde la vinculación entre familias de ulemas, de notables ur-

59 Para evitar la creación de un espacio de impunidad, la teoría legal sobre la usospecha fundamentada» fue desarrollándose progresivamente; cf. Serrano, D., «The Application of Penal Law in Almoravid Courts", Masud, M. Kh., Peters, R. y Powers, D., eds., Dispensing Jutice in Muslim Courts: Qädīs, Procedures, and Judgments, Leiden (en prensa).

${ }_{60}$ Cf. Masud, M. Kh., «Procedural Law between Traditionists, Jurists, and Judges: the Problem of yamin ma 'al-shähid», Al-Qanțara, XX (1999), 389-416.

${ }^{61} \mathrm{Q}$ āịi 'Iyāud, Tartīb al-madārik, VI, 110.

${ }^{62}$ Entre los contemporáneos de al-Lu'lu'î, puede señalarse en este sentido a Hammād b. Šaqrān b. Hammād (Ibn al-Faradī, Ta'rȳ 'ulamā' al-Andalus, n. ${ }^{\circ}$ 388) o a Ibrähìm b. 'Ubayd Allāh al-Ma'āfiri (id., n. ${ }^{\circ} 41$ ). 
banos, y la propiedad rural aparece de manera más diáfana. La descripción de la actividad económica de Muhammad se tiñe en la pregunta hecha por su hermano de tintes religiosos, como era de esperar; sin embargo, despojada de este carácter, se revela como un ejemplo nítido de la acción de un poderoso propietario rural, que destina sus excedentes al comercio y a la mejora de sus fincas, construyendo una red clientelar en las vecinas comunidades de campesinos. No es posible saber hasta qué punto esta fórmula fue excepcional, pero en todo caso podría servir para matizar la definición de las relaciones entre las comunidades campesinas y los notables ( $a^{\prime} y \bar{a} n$ ) de las ciudades.

\title{
RESUMEN
}

En este artículo se estudian dos aspectos de la investigación sobre delitos de sangre en al-Andalus. En primer lugar, la tadmiya, inculpación hecha por una persona gravemente herida contra su atacante. En segundo lugar, la qasāma, el juramento cincuentenario que podían hacer los parientes masculinos de la víctima de un crimen contra alguien a quien acusaban de haberlo cometido. Estos dos procedimientos se examinan a través de varios casos, documentados históricamente, en que se pusieron en práctica. Las opiniones de los juristas no siempre fueron unánimes a este respecto, bien por diferencias entre las escuelas legales (mālikíes y šāfi'íes), bien por divergencias dentro de la propia escuela mālikí. Tal como puede observarse en los casos estudiados, las actitudes personales, así como las relaciones sociales y económicas, representaron un papel importante en las investigaciones sobre los delitos de sangre.

\begin{abstract}
Two procedures of criminal investigation in al-Andalus are presented in this paper. First, the tadmiya, an accusation made by a seriously injured person against his or her assailant; secondly, the qasäma, an oath pronounced 50 times by the male relatives of a victim of murder accusing somebody of the crime. These two procedures are examined through several cases, historically documented, of their actual practice in al-Andalus. Jurists' opinions were not always unanimous on these issues, owing to differences in school affiliations (Mālikites against Shäfi'ites) and to divergences inside the same school. Personal attitudes and social and economic relationships also played an important role in criminal investigations, as attested in the cases under study.
\end{abstract}

